\title{
Research on the Cultivation of College Students' Engineering Ability Based on Innovative Training Program
}

\author{
Yu-feng $L U^{1, a, *}$ \\ ${ }^{1}$ School of Mechanical and Automotive Engineering, QILU University of Technology, \\ Daxue Road, Jinan, China \\ aluyf78@126.com \\ ${ }^{*}$ Corresponding author
}

Keywords: Engineering Ability, Innovative Training Project, Competition Oriented.

\begin{abstract}
How to cultivate the engineering ability of college students is an international problem which attracts the attention of the educational circles. A method based on college students' innovative training project is put forward for the engineering ability training. Several basic quality of college students' engineering ability can be cultivated by innovative training programs. The case method is adopted to carry out moral education in the process of innovation training. The method of grouping and cooperation to complete various tasks are used to train college students' communication and teamwork spirit. Students' innovative spirit can be cultivated by science and technology competition. So the engineering ability of college students can be improved through innovative training. At the same time it can also help teachers to improve their engineering ability in the process of guiding college students' innovative training.
\end{abstract}

\section{Introduction}

The cultivation of engineering consciousness and engineering ability of college students is a common problem in the world. In order to promote the cultivation of College Students' engineering ability the training plan of excellent engineers and the work of engineering education accreditation have also been promoted in recent years in our country [1].

At present, the cultivation of Engineering Science and technology talents in our country focuses on students' learning of professional knowledge. The cultivation of students' ability in engineering training is not enough. From the perspective of engineering education, training objectives are proposed from the perspective of mastering professional knowledge due to the lack of the concept of engineering education. Some engineering majors can find the training needs of the relevant engineering ability, but lack of organic connection with the curriculum objectives. The curriculum objectives can hardly be found in a clear expression of engineering ability training [2]. Therefore, it is necessary to develop a new curriculum to cultivate engineering consciousness and engineering ability.

The 20 basic qualities of high-level engineering talents are put forward by the Chinese Academy of Engineering on the basis of the investigation of the basic quality of the high-level engineering and technical personnel at home and abroad in 2007. And questionnaire survey was carried out. The survey results showed that: the character and occupation moral, lifelong learning ability, solid professional foundation, professional engineering and technical skills, to solve problems in Engineering Science and 
technology ability, multidisciplinary team cooperation ability are generally considered to be the core of qualities which engineers should have[3].

According to our exploration and practice for many years a method of cultivating engineering consciousness and engineering ability based on innovative training project is put forward in this paper. This paper expounds how to cultivate the basic qualities of engineer in the innovation training project.

\section{Moral Education}

The innovative training curriculum contains rich moral education content. Abundant allusions help to cultivate the socialist core values and scientific spirit. The moral education was executed using education elements in the curriculum and teaching process in the course of classroom teaching. Students' scientific spirit of persistent exploration was developed by using moral education [4].

For example, in the process of teaching students copying homework problems were found. Combined with the famous example, the important meaning of dedication, honesty and trustworthiness, the spirit of science to students were expounded immediately. The students' professional ethics and teamwork spirit were trained through out the course.

\section{Professional Moral Cultivation}

In order to cultivate college students' noble moral character and professional ethics, it is very important to integrate moral education into the course of innovation training. Combining the teaching process for students to copy homework significance of dedication was explained to students on the end of the first chapter.

Learning is the bounden duty of the students and study hard is a kind of professionalism. Serious work independently is the students obey the moral sign of occupation. Love is the love of their jobs and students are the love of learning which is to do homework carefully. Dedication is an important way to serve the social contribution and which is the fundamental survival of all walks of life too. It is the basic task for the students to acquire knowledge and finish their studies. Good morality dedication is formed in the process of learning for future work. College students can better serve the society and get more chances to get a raise after they enter the society.

\section{Team Spirit Training}

"Team spirit" actually contains two meanings: one is the ability to communicate with others; the two is the ability to cooperate with others. Large operations can be arranged in the course of innovative training projects. Task assignment is an innovative approach. Students will be grouped, so that students in groups to complete the work unit. This is a team approach to complete a task, the overall plan of the arrangement, material collection and arrangement of content, until the team's defense by all members to complete. Team members need to communicate and coordinate with each other to reach agreement on the structure, content and division of work. The task also needs students try to make the other students understand and understand what they want to express in the oral expression. In cooperation with others and share the results and process of reciprocity a comprehensive exercise communication ability and team spirit is conducted. Team spirit can be cultivated by group cooperation [5]. 


\section{Teachers' Engineering Ability Training}

There are two ways are put forward to improve the practical ability of teachers according to the actual situation of the school [6].

\section{Improving Practical Ability by Combining Vocational Skills Competition}

Teachers should not only teach the basic theory of curriculum, but also guide the practical application of curriculum. Only the teachers have the ability to work can train students' engineering ability. Vocational skills competition provides a way for teachers to cultivate engineering ability.

The competition of engineering application technology teachers in colleges and universities is a national competition focused on improving the practical ability of teachers. Competition for the current status of teachers in colleges and universities in the country to carry out technical competitions. To participate in the competition can improve the teachers' engineering skills and enhance the engineering practice experience. The principle of the competition is adhering to the direction of engineering technology application, integration of excellent engineers and technical personnel training requirements. By participating in activities to improve the teachers' personal practical skills, but also to promote the teachers to update their knowledge and enrich the teaching cases.

\section{Participate in Enterprise Practice}

Organizing teachers to enterprise practice is an important form of in-service training for teachers, which is an effective way to improve teachers' professional skills and practical teaching ability. Through the practice of the enterprise, the construction of the teachers can be strengthened. It is of great significance to promote the reform of education and teaching and the transformation of the mode of personnel training. In the process of participating in the project, we can train the teachers' quality of Engineering thinking. By learning new knowledge, new skills, new techniques and new methods applied in production practice we can continuously improve the teaching plan.

Teachers should plan to take part in the enterprise, rather than as a practice study tour. Only in this way can teachers get involved in practical problems as much as possible. Teachers can enrich their practical experience and improve their practical skills. Teachers should take an active part in the research project. Promote the transformation of scientific research achievements into productive forces. While participating in the project practice the teacher can expand the field of vision and improve the team cooperation ability.

\section{Practice Ability Training}

Each training project is formulated to reflect the characteristics of the integrated innovation practice teaching content. The practice is reflected in each basic training program. Students' practical ability and students' engineering quality are cultivated in these programs. The setting of practical projects should embody the following three principles.

\section{Project Setting Should be Career Oriented}

Occupation is the talent needs of the society and the employer is the way after graduation. The fundamental goal of cultivating talents in colleges and universities is to cultivate the students to be welcomed by the society. So that every graduate has a good 
way out. For many years, with the rapid economic and social development, the talent training objectives and curriculum of Chinese universities can not be adjusted in time. Personnel training and social needs caused a huge waste of talent. The training mode is to adhere to the occupation oriented. Looking back in time to respond to the needs of society for talents. Setting up innovative practice projects according to the needs category. As for the students to continue their studies to strengthen the cultivation of scientific research and innovation ability. To strengthen the cultivation of students' ability of practice and innovation. For the students who start their own businesses to strengthen the cultivation of their entrepreneurial ability.

\section{Project should be based on Students}

Students are the main body of talent training and the central link of higher education. The ultimate goal of all training models should be implemented to students. Students are the main participants and the main beneficiaries of innovation training. Therefore, taking the students as the main body is to give full play to the students' main position in the practice teaching of innovation. Setting up innovative training programs with the aim of students' needs. Students' autonomous learning as the main way of learning. To make students learn transfer from passive learning to active learning and improve the pertinence and effectiveness of the cultivation of innovative ability.

\section{Project Setting should Reflect the Main Line of Innovative Practice}

Innovation practice is the main channel for the cultivation of innovation ability, but also the specific activities of students to carry out innovative projects. In the whole innovation ability training mode, the innovation practice is a main line. The practice of innovation is to set up and carry out different projects according to the requirements of different grades and different levels of students in the course of implementation. For different levels of students to set up different innovative practice courses. Different students participate in different levels of innovation and competition will achieve the goal of innovation ability training.

\section{Using Competition to Cultivate Innovative Spirit}

In the process of the implementation of the innovation project, according to the different modules of the innovative training projects to set up different levels of innovation competition unit. Improve the teaching effect; stimulate the students' enthusiasm, initiative, and creativity. In the different stages of teaching, students are required to complete the corresponding works according to their respective requirements, and then conduct the stage competition. In the competition, each project team needs to send representatives to introduce the work. The key is that the conception of the work and the innovation, use of knowledge, the main problem to solve. And then exercise the students' divergent thinking. Other groups of students can be questioned, the students to reply. Finally, the evaluation team composed of students and teachers, the project as a result of the competition score. The result of the competition is also the basis for recommending the work to a higher level. At the end of each module level innovation training program, the organization is recommended for a larger range of works. This teaching method organically combines teaching and competition, stimulates students' learning enthusiasm and stimulates students' creative inspiration. So that the students' learning attitude has changed, and the students' sense of urgency is improved. Enhance the sense of accomplishment of students; enhance the team spirit of 
students. So that the students' design ability, practical ability, organization and coordination ability, engineering practice ability, writing ability, expression ability has been a comprehensive exercise and improve, this is the ordinary classroom teaching incomparable.

\section{Conclusions}

The aim of the project is to cultivate students' engineering ability. The basic qualities of engineers are divided into six categories. On the basis of the innovation training of college students, the paper establishes the long-term operation mechanism of engineering ability training. Moral education should be carried out before the engineering ability training. Moral education class can be used to instill the quality of engineering thinking. The innovative spirit of college students may be cultivated by using the science and technology competition. To cultivate college students' engineering ability teachers should possess practical engineering ability. So several methods are proposed to improve the engineering ability of teachers.

\section{Acknowledgement}

The results of this study are funded by Postgraduate Education Innovation Program of Shandong Province (Grant NO.SDYY14025) and Teaching Research Project of QILU University of Technology (Research on Demand Forecasting of Applied Talents in Shandong Province Based on Large Data).

\section{References}

[1] Liu Jiangnan, Han Xu, Zhou Changjiang, et al., "Teaching method" to cultivate students' engineering consciousness and engineering ability, China University Teaching.11(2012)56-58.(In Chinese)

[2] Li Hongmei, Jiang Zhibin,Zheng Yihui, University Curriculum System Reformation to Strengthen the Cultivation of Engineering Ability, Research in Higher Education of Engineering.5(2013)140-144. (In Chinese)

[3] Hao Zhixiu, Ji Linhong, Feng Juan, Exploration and Practice of Training the Junior University Students' Engineering Ability with CDIO Concept: A Case Study of Mechanical Basis Practice Course, Research in Higher Education of Engineering. 5(2009)36-40. (In Chinese)

[4] Yufeng LU, Hidden the Moral Education in Teaching of "Automobile Application Engineering", in: Pavlova, M, Zeng, XY(Eds), Advances in Social Science Education and Humanities Research, ATLANTIS PRESS, PARIS, 2016, pp.582-585.

[5] Xu Xiao, Zhai Jingmei, Research on the cultivation of team spirit in the teaching of Mechanical Foundation Series, National Conference on Mechanical Design Teaching. China, (2009)492-497. (In Chinese)

[6] YuFeng LU, Practice of Improving Young Teachers' Engineering Ability in Application Oriented Universities, in: Xiaonan Xiao, Frank Bünning (Eds), Advances in Social Science Education and Humanities Research, ATLANTIS PRESS, PARIS, 2016, pp. 163-166. 